Topics in Cognitive Science 4 (2012) 396-403

Copyright () 2012 Cognitive Science Society, Inc. All rights reserved.

ISSN: $1756-8757$ print / 1756-8765 online

DOI: $10.1111 / \mathrm{j} .1756-8765.2012 .01195 . \mathrm{x}$

\section{The Original Sin of Cognitive Science}

\author{
Stephen C. Levinson \\ Max Planck Institute for Psycholinguistics, and Donders Institute for Brain, Cognition and Behaviour, Radboud \\ University, Nijmegen
}

Received 29 June 2011; received in revised form 6 August 2011; accepted 17 December 2011

\begin{abstract}
Classical cognitive science was launched on the premise that the architecture of human cognition is uniform and universal across the species. This premise is biologically impossible and is being actively undermined by, for example, imaging genomics. Anthropology (including archaeology, biological anthropology, linguistics, and cultural anthropology) is, in contrast, largely concerned with the diversification of human culture, language, and biology across time and space-it belongs fundamentally to the evolutionary sciences. The new cognitive sciences that will emerge from the interactions with the biological sciences will focus on variation and diversity, opening the door for rapprochement with anthropology.
\end{abstract}

Keywords: Language diversity; Cultural diversity; Evolutionary processes

Darwin's real revolution consisted in the epistemological reorientation that had to occur before the variational mechanism could even be formulated. It was a change in the object of study from the average or modal properties of groups to the variation between individuals within them. That is, variation itself is the proper object of biological study, for it is the ground of biological being. (Lewontin, 1983, p. 3)

Beller, Bender, and Medin in their introduction to this issue offer a series of possible reasons for the failed love affair between anthropology and the cognitive sciences. Some of the points are well taken, but I suspect that the major explanations lie elsewhere. First, it is no secret that cultural anthropology largely went on postmodernist holiday in the 1980s and has not come back yet. Second, the terms of any marriage were dictated by the dominant partner, and that meant anthropologists were expected to deliver quantitative data-a form of data compression that ill suits anthropological scruples about the rich local texture of events, and for which sophisticated training is largely missing in the relevant graduate

Correspondence should be sent to Stephen C. Levinson, Max Planck Institute for Psycholinguistics, P.O. Box 310, NL-6500 HD Nijmegen, The Netherlands. E-mail: stephen.levinson@mpi.nl 
departments. In addition, the only desirable deliverable recognized by the cognitive science of the day was the universal, as in Berlin and Kay (1969). But the main reason is simpler. The cognitive sciences have had zero interest in exactly what anthropology sets out to deliver, namely information on human diversity.

Let me enlarge. The cognitive science revolution was based on a fundamental idealization, the myth of "the human mind.' Research on human vision, audition, memory, categorization, or the like presumes a single mental capacity, idealized away from all the "noise" of individual variation or systematic cultural diversity. Fodor's $(1975,1983)$ doctrines of the language of thought and modularity of mind capture the ideology of classic cognitive science exactly. The job of cognitive science, it was assumed at the outset, was to deliver blueprints of universal human cognitive capacities. Nowhere was this odder than in the study of language: It too had to conform to a single mental module, despite the striking diversity of languages in every level of structure and organization (Evans \& Levinson, 2009). In the language sciences, there is a slow, growing realization that this diversity is the most striking feature of human language - there is no other animal on the planet, as far as we know, which has such myriad variants of form and meaning at every level in its communication system. What this feature of language ought to convey to us with special force is that culture is the peculiar human adaptive trick that has made it possible for us to invade and dominate almost every terrestrial niche on the planet. Classical cognitive science treats humans like an asocial species without culture, and in doing so, it misses the heart of the human phenomenon.

This is the original sin of the cognitive sciences - the denial of variation and diversity in human cognition. Trying to convert our errant psychological colleagues to the errors of their ways may prove difficult, but there is luckily no need. For a giant tsunami is about to burst over classical cognitive science, and it will sweep away the old guard. The first tremors came in the form of the discovery of brain plasticity - the ability of the brain as a physiological organ to adapt long term to specific input. We now know that the spatial skills of taxi drivers are reflected in, and caused by, enlargements of the neural tissue associated with navigation (Maguire et al., 2000). And we know that the brains of literate persons are substantially rewired compared with their illiterate siblings (Carreiras et al., 2009; Petersson et al., 2007). Blind humans use the visual cortex for language and, amazingly, echolocation (Thaler, Arnott, \& Goodale, 2010), reinventing in a lifetime the 50 million-year-old adaptation of the bats. To a very real extent, we are what we do, we think what we experience. The structure of the brain comes to reflect the use we make of it, affording new cognitive exploitations and closing down others. This is such a departure from classic cognitive science that even the field of neurocognition has only partially adapted to the new picture, continuing to weed out variation by selecting right-handers or morphing brains, rather than grasping that variation is the essential data, the levers that give one insight into how mental processes work.

But the big one, the earthquake that should shake up the cognitive sciences once and for all, comes from genetics. The best way of cracking the genetic code, finding out how genes do their work, is to exploit the natural variation in the population. Most progress so far has made use of syndromes, clinical conditions whose link to genes can provide a lever into the 
underlying cascades of genes that control higher level cognitive functioning. In this way, for example, the role of FOXP2 in language was discovered (Fisher, Vargha-Khadem, Watkins, Monaco, \& Pembrey, 1998). But now the game has changed, made possible by whole genome sequencing. The normal variation in the population is being exploited, so that we now know, for example, that the T-allele of the KIBRA gene is associated with better long-term memory, that it is expressed in memory areas of the brain, and that the distribution of this variant varies systematically across populations (Papassotiropoulos et al., 2006). In laboratories around the world, the race is now on in this new field of brain-imaging genomics to deliver news about how the genes construct a brain that delivers higher level cognition (Thompson, Martin, \& Wright, 2010).

Imaging genomics is a game changer because it shifts the focus from the old uniformitarianism of classical cognitive science in a completely different direction toward a keen interest in differences in human biology, experience, and performance. As we learn more about these mechanisms, the ways in which cultural environments play into the epigenetic factors that control gene expression will move center stage: How do genes come to build the enlarged hippocampus of the taxi driver, or the much enlarged fiber-bundles of the corpus callosum in the literate? Imaging genomics is going to commandeer the main funding sources, and it is going to overturn the professional applecart in the cognitive sciences, making paupers out of mainstream cognitive psychologists and princes out of experts on individual differences.

A new focus on human diversity and variation in performance might seem to lose the wood for the trees: Are not the basic processing mechanisms, the core algorithms, the main neural pathways going to remain constant under the variation? This may turn out to vary across the faculties, for example, between vision versus olfaction, or working memory versus long-term memory, and so forth. But let me turn to language, the domain I know most about. First, the new information suggests that there are fundamental differences across individuals in the same population with respect to the underlying neural circuitry. For example, the arcuate fasciculus - the white fiber bundle connecting (roughly) Wernicke's and Broca's areas-is in some individuals only developed in the left hemisphere; in others it is fully bilateralized, correlating with better verbal recall (Catani et al., 2007). Two thirds of women show higher degrees of bilateralization than nearly all men. Another major divide is between those with familial left-handedness in their genealogies (about $40 \%$ of the U.S. population) and those without. The familial lefthanders seem to use a less syntactic, more semantic/lexical style of processing (Townsend, Carrithers, \& Bever, 2001). The upshot of these findings is that different wetware and different algorithms can be used to produce passingly similar performance, because the output is culturally regulated. One function of culture is thus to mask individual differences, making phenotypic clones out of us all. ${ }^{1}$ The other function is to differentiate, producing spectacular pseudo-speciation where little biological difference exists.

In this context, it makes sense to ask: Do different languages induce different algorithms and exercise different neural circuitry? The answer is almost certainly yes. First, languages differ so much that they inevitably require different processing algorithms. Sign languages use a completely different input/output modality. Tone languages require tonal contour 
processing in the 250-ms time band; other languages do not. Some languages use extensive morphology; others, none. Languages with completely free word order cannot be processed using a phrase-structure parser. If the algorithms are different, the neural circuitry should be distinct, and the indications are that this is so. For example, highly inflected languages like Finnish have a distinct neurocognitive signature (Lehtonen et al., 2009). Similarly, Chinese word recognition involves much more bilateral activation than English, and English is itself divergent from Spanish (Valaki et al., 2004). Even the tonal versus nontonal dialects of Dutch show differences similar to Chinese versus English (Fournier, Gussenhoven, Jensen, \& Hagoort, 2010). Not surprisingly perhaps, using a sign language changes the very structure of the brain (Allen, Emmorey, Bruss, \& Damasio, 2008). Rather than a single core language-processing system, what we see is endless variations on a theme.

So the variation is there, regimented by culture both within populations and across populations, and instead of treating it like noise we should be treating it like a major source of insight, in the same way that geneticists use mutations or knock-out mice. For example, suppose you have a theory of language acquisition that predicts that learning prefixes is harder than learning suffixes: Then you can study infants learning a sample of Mayan languages that naturally titrate all the possible affix orders (Pye, Pfeiler, De León, Brown, \& Mateo, 2007). Or suppose, following the long Western tradition from Kant to Piaget, you have the theory that spatial cognition is fundamentally egocentric in character, then you can go and study how children memorize spatial arrays in cultures where people do not know their lefts from their rights (Haun, Rapold, Janzen, \& Levinson, 2011; Levinson, 2003). You can follow that up by checking the spatial responses of all the members of our great ape family: You will find that Kant is wrong, and not knowing our lefts and rights is part of our wild type (Haun, Rapold, Call, Janzen, \& Levinson, 2006). The insights offered by a comparative psychology over species and cultures offer a much better foundation for cognitive science than our current reliance on Western undergraduates (Henrich, Heine, \& Norenzayan, 2010).

Languages are a very rough proxy for cultures: There are around 7,000 distinct languages and at least as many cultures. That distinct languages enforce different modes of processing can also stand as a proxy for other kinds of cultural variation. Consider, for instance, the extraordinary prowess of navigation among hunter gatherers (Levinson, 2003 ) or the mnemonic powers of illiterate peoples (in one New Guinea society where I currently work, 50,000 words of a new song cycle are learned in just 10 rehearsals). These are cultural specializations of cognition as extreme as the professional musician or the theoretical physicist.

Once the ideological myth of "the human mind" is broken by these developments, one can expect a renewed interest in cultural and social variation, because cultures offer thousands of natural laboratories for the study of human performance under specific conditions. There are still societies with minimal divisions of labor, where hunting skills in forest or sea provide dinner, where there is little education or literacy, where kinship algebra is extensive but numeracy lacking, where there is no pictorial representation, and where vast repositories of traditional knowledge are passed only by word of mouth. In some societies, the diversity is fractal. Take a traditional South Indian village, with say 20 castes, each is endogamous 
forming a distinct genetic population, is a cultural microcosm with its own kinship system and ritual, and offers a distinct profession with training from an early age (from goldsmithing to bullock shoeing, leather working to weaving, priesthood to musicians; see Beck, 1972). Such a fragmentation of expertise, a specialism of human development, and a wealth of diverse ecologies offers affordances equivalent to the animal models (the knock-out mice, the song bird species, drosophila, and so on) in the biological sciences. It is moreover a laboratory that is fast being eroded by globalization, so we may be the last generation that has the wealth of material so readily in hand.

The renaissance of interest in human variation and diversity is now inevitable. The only open question might be what framework we will use to organize data, theory, and method in the new cognitive sciences. But here the answer is obvious: There is just one framework for thinking about patterned variation in the biological and cultural realms, namely the theory of evolution. The extension of the theory from purely biological to biological-plus-cultural phenomena has been worked out over the last 30 years (see, e.g., Boyd \& Richerson, 2004), and it has been conceived variously, for example, as twin tracks of evolution with feedback relations between them, or as feedback relations between ecological niche and organism (OdlingSmee, Laland, \& Feldman, 2003). Recently, there have been singular successes in the application of evolutionary methods to the cultural world (Dunn, Greenhill, Levinson, \& Gray, 2011; Steele, Jordan, \& Cochrane, 2010). In the middle of these processes is the "endophenotype," the brain, and the cognitive tricks that make the behavior possible, which is both subject to and constitutive of the special selective environment of a cultural species.

One intriguing possibility is that these interconnections between biology and culture are much more intimate than previously imagined. It seems likely that very small differences in population genetics can seed cultural diversity by slightly biasing the transmission success of cultural variants. For example, differences in the frequencies of the alleles of two genes involved in brain development correlate strongly with the presence or absence of tone across languages (Dediu \& Ladd, 2007). It is probable that small variations in the shape of the vocal tract will be found to correlate with phonemic inventories around the world. Variation in special cognitive skills, from navigation to musical abilities, may also be seeded in this way (note that there is no biological determinism here-very small population differences may be sufficient to make specific cultural forms a little more likely to arise).

So what role will anthropology as a discipline play in these developments? Anthropology in the American "four fields" sense (biological, archaeological, cultural, and linguistic anthropology) will clearly be central-developments in twin-track theory have come out of biological anthropology and archeology interacting with biology. The linguists are not far behind, because they are in possession of the form of cultural life that manifests the most spectacular cladistic structure over deep time periods (Dunn et al., 2005). But the role of cultural anthropology is much less clear, due to the history of the subdiscipline. Recall that cultural anthropology was in 1950 all set to embark on a grand project of cataloguing cultural features around the world, with a view to the systematic investigation of the relationships between them (Murdock, 1949). But then the rise of structuralism posed a systematic challenge to such trait analysis: The meaning and function of elements were viewed as depending on the system that they function within. Such holistic analysis made systematic 
cross-cultural comparison difficult, and progress was made in only a few fields like color and kinship. The postcolonial period encouraged severe self-censure. On this weakened foundation for a systematic science, the postmodern emphasis on the subjective, the interplay between observer and observed, and the literary qualities of ethnography came to the fore. This leaves English-speaking cultural anthropology in a condition largely unfit for serious cooperation with the empirical sciences (the French invented postmodernism, but treated it like bad wine, for export only, and there are other schools that have retained an empirical orientation).

The loss of potential collaborators in cultural anthropology is a matter for deep regret. For what cultural anthropologists have is the kind of grasp of the cultural environment as a whole that is essential for good cross-cultural survey and experiment. You cannot devise an ecologically valid experiment without understanding the ecology, and to understand the cultural ecology you must invest years, learning the language, the mores, and the motivations of the locals. That is why much of what passes for cross-cultural work in cognition these days is not reliable. Researchers from psychology drop in to the jungle, now within easy reach of some airport, and conduct experiments on some local population, working through an interpreter with inappropriate computer interfaces or stimuli. Dozens of studies on language, musical cognition, numerical cognition, and the like could be cited. Results contrary to universal hypotheses are unreported, and we get little nearer to the truth.

What to do then if you are a cognitive psychologist looking for collaborators who can help you unlock the marvelous cognitive diversity locked up in the cultures of the world? Look for a cultural anthropologist who has escaped postmodernism (try those trained in the non-English-speaking world), or a linguistic anthropologist or anyone branding oneself as a cognitive anthropologist (they are dissenters), and failing that behavioral ecologists, archeologists, and biological anthropologists with long-term field experience. Do not treat your anthropological collaborators as junior partners who merely facilitate work in the field-they are the parties with the deep contextual knowledge that can help interpret the theoretical import of the results.

Finally, there is a view that I acquired from Edmund Leach, the great anthropologist who self-identified with the early cognitive science movement, ${ }^{2}$ that anthropology (in the enlarged "four fields" sense) has a special role to play in the crowded world of today's subsubdisciplines. That role is to retain the global, overarching perspective on human life that is increasingly lost through academic specialization. It is a role that is substantially reinforced through the first-hand experience of immersive fieldwork. The early cognitive science movement likewise tried to keep its head above the waters and formulate general principles of cognition and computation. The two movements have thus a natural affinity, especially in the changing circumstances I have outlined.

\section{Notes}

1. By "cloning"' around one standard phenotype in one population, and another in another, populations differences - the efflorescence of cultural diversity-is automatically 
brought about. On the phenotypic "buffering"' of underlying genetic variation, see Le Rouzic and Carlborg (2008).

2. "My deepest concerns were with what is now discussed under such grandiose labels as semiotics and cognitive science'" (Leach, 1984, p. 19).

\section{Acknowledgments}

The author thanks Penelope Brown, Asifa Majid, Mark Dingemanse, Dan Dediu, and two anonymous reviewers for comments on this article, and also Russell Gray for the Lewontin quote.

\section{References}

Allen, J., Emmorey, K., Bruss, J., \& Damasio, H. (2008). Morphology of the Insula in relation to hearing status and Sign Language experience. Journal of Neuroscience, 28(46), 11900-11905.

Beck, B. (1972). Peasant society in Konku: A study of right and left subcastes in South India. Vancouver: University of British Columbia Press.

Berlin, B., \& Kay, P. (1969). Basic color terms: Their universality and evolution. Berkeley, CA: University of California Press.

Boyd, R., \& Richerson, P. (2004). Not by genes alone. Chicago: Chicago University Press.

Carreiras, M., Seghier, M. L., Baquero, S., Estévez, A., Lozano, A., Devlin, J. T., \& Price, C. J. (2009). An anatomical signature for literacy. Nature, 461(7266), 983-986.

Catani, M., Allin, P. G. A., Husain, M., Pugliese, L., Mesulam, M. M., Murray, R. M., \& Jones, D. K. (2007). Symmetries in human brain pathways predict verbal recall. Proceedings of the National Academy of Sciences of the United States of America, 104(43), 17163-17168.

Dediu, D., \& Ladd, D. R. (2007). Linguistic tone is related to the population frequency of the adaptive haplogroups of two brain size genes, ASPM and Microcephalin. Proceedings of the National Academy of Sciences of the United States of America, 104(26), 10944-10949.

Dunn, M., Greenhill, S. J., Levinson, S. C., \& Gray, R. D. (2011). Evolved structure of language shows lineagespecific trends in word-order universals. Nature, 473, 79-82.

Dunn, M., Terrill, A., Reesink, G., Foley, R. A., \& Levinson, S. C. (2005). Structural phylogenetics and the reconstruction of ancient language history. Science, 309, 2072-2075.

Evans, N., \& Levinson, S. C. (2009). The myth of language universals: Language diversity and its importance for cognitive Science. Behavioral and Brain Sciences, 32(5), 429-492.

Fisher, S. E., Vargha-Khadem, F., Watkins, K. E., Monaco, A. P., \& Pembrey, M. E. (1998). Localisation of a gene implicated in a severe speech and language disorder. Nature Genetics, 18, 168-170.

Fodor, J. A. (1975). The language of thought. New York: Crowell.

Fodor, J. A. (1983). The modularity of mind. Cambridge, MA: MIT Press.

Fournier, R., Gussenhoven, C., Jensen, O., \& Hagoort, P. (2010). Lateralization of tonal and intonational pitch processing: An MEG study. Brain Research, 1328, 79-88.

Haun, D. B. M., Rapold, C. J., Call, J., Janzen, G., \& Levinson, S. C. (2006). Cognitive cladistics and cultural override in Hominid spatial cognition. Proceedings of the National Academy of Sciences of the United States of America, 103 (46), 17568-17573.

Haun, D. B. M., Rapold, C. J., Janzen, G., \& Levinson, S. C. (2011). Plasticity of human spatial memory: Spatial language and cognition covary across cultures. Cognition, 119, 70-80. 
Henrich, J., Heine, S. J., \& Norenzayan, A. (2010). The weirdest people in the world? Behavioral and Brain Sciences, 33, 61-135.

Le Rouzic, A., \& Carlborg, Ö. (2008). Evolutionary potential of hidden genetic variation. Trends in Ecology \& Evolution, 23(1), 33-37.

Leach, E. R. (1984). Glimpses of the unmentionable in the history of British social anthropology. Annual Review of Anthropology, 13, 1-24.

Lehtonen, M., Vorobyev, V., Soveri, A., Hugdahl, K., Tuokkola, T., \& Laine, M. (2009). Language-specific activations in the brain: Evidence from inflectional processing in bilinguals. Journal of Neurolinguistics, 22(5), 495-513.

Levinson, S. C. (2003). Space in language and cognition: Explorations in cognitive diversity. Cambridge, England: Cambridge University Press.

Lewontin, R. C. (1983). Darwin's revolution. New York Review of Books, 30, 21-27.

Maguire, E. A., Gadian, D. G. et al. (2000). Navigation-related structural change in the hippocampi of taxi drivers. Proceedings of the National Academy of Sciences of the United States of America, 97(8), 4398-4403.

Murdock, G. P. (1949). Social structure. New York: The MacMillan Company.

Odling-Smee, J. F., Laland, K. N., \& Feldman, M. W. (2003). Niche construction: The neglected process in evolution. Monographs in Population Biology Series, 37. Princeton, NJ: Princeton University Press.

Papassotiropoulos, A., Stephan, D. A., Johnsrude, I. S., Good, C. D., Ashburner, J., Frackowiak, R.S., \& Frith, C. D. (2006). Common Kibra alleles are associated with human memory performance. Science, 314(5798), 475-478.

Petersson, K. M., Silva, C., Alexandre Castro-Caldas, A., Ingvar, M., \& Reis, A. (2007). Literacy: A cultural influence on functional left-right differences in the inferior parietal cortex. European Journal of Neuroscience, 26(3), 791-799.

Pye, C., Pfeiler, B., De León, L., Brown, P., \& Mateo, P. (2007). Roots or edges? Explaining variation in children's early verb forms across five Mayan languages. In B. Pfeiler (Ed.), Learning indigenous languages: Child language acquisition in Mesoamerica (pp. 15-46). Berlin: Mouton de Gruyter.

Steele, J., Jordan, P., \& Cochrane, E. (Eds.). (2010). Cultural and linguistic diversity: Evolutionary approaches. Philosophical Transactions of the Royal Society, B, 365, 1559.

Thaler, L., Arnott, S. R., \& Goodale, M. A. (2010). Human echolocation I. Journal of Vision, 10(7), 1050.

Thompson, P. M., Martin, N. G., \& Wright, M. J. (2010). Imaging genomics. Current Opinion in Neurology, 23(4), 368-73.

Townsend, D. J., Carrithers, C., \& Bever, T. (2001). Familial handedness and access to words, meaning, and syntax during sentence comprehension. Brain and Language, 78(3), 308-331.

Valaki, C. E. M., Maestu, F., Simos, P. G., Zhang, W., Fernandez, A., Amo, C. M., Ortiz, T. M., \& Papanicolaou, A. C. (2004). Cortical organization for receptive language functions in Chinese, English and Spanish: A cross-linguistic MEG study. Neuropsychologia, 42(7), 967-979. 